\title{
House prices and bank credits in Malaysia: an aggregate and disaggregate analysis
}

\begin{abstract}
The paper investigates the long run behavior of house prices and their dynamic interactions with bank credits, real output and interest rate for the case of Malaysia. Apart from the aggregate house prices, the analysis also covers various house price sub-indices, namely, the terraced house price index, the semi-detached house price index, the detached house price index and the high-rise price index. From the aggregate perspective, we note the presence of a long run relation among the variables. Moreover, the findings suggest the long run causality that runs from the included variables to both the aggregate house prices and bank credits. Dynamic interactions between house prices and bank credits are further reflected by the generated impulse-response functions. The disaggregate analysis indicates that only the terraced house price index forms a long run relation with bank credits, real output and interest rate with their dynamic interactions to mimic well the aggregate systems. Still, a further analysis reveals that shocks to the terraced house price tend to diffuse to other segments of housing markets. Among the housing types, the detached house price is relatively segmented and affected only indirectly through the diffusion/ripple effect. These findings bear important implications for macroeconomic stability, monetary policy and investment decisions.
\end{abstract}

Keyword: House prices; Aggregate and disaggregate analysis; Cointegration; VAR; Malaysia 